\title{
Digital Competence and Capability Frameworks in Higher Education: Importance of Life-long Learning, Self-Development and Well-being
}

\author{
D. Biggins ${ }^{1, *}$, D. Holley ${ }^{2}$ and M. Zezulkova ${ }^{3}$
}

${ }^{1}$ Bournemouth University, Centre for Excellence in Learning, Talbot Campus, Poole, United Kingdom, BH12 5BB

${ }^{2}$ Bournemouth University, Centre for Excellence in Learning, Talbot Campus, Poole, United Kingdom, BH12 5BB

${ }^{3}$ Charles University, Institute of Communication Studies \& Journalism, Smetanovo nab. 6, Prague, Czech Republic, 11000

\begin{abstract}
The paper compares the EU's 2013 and 2016 digital competence (DigComp) framework with the UK education's 2009 and 2015 digital capabilities (DigCap) framework. The similarities are in the increased focus on data within privacy/overall literacy and the inclusion of well-being. Among the differences, DigComp focuses on life-long learning whereas DigCap is more holistic. This is explained by diverse target audiences, as DigComp has to be relevant to various stakeholders across the EU, whilst DigCap serves the UK higher and further education sector. Although education is dominant within DigCap, both frameworks agree on the importance of digital skills, knowledge and attitudes to the fields of education, training and employment. The paper discusses a UK HE case study of a technology enhanced learning toolkit. It concludes by arguing for a human-centred approach to digital competence and capability frameworks, in which learning, self-development and wellbeing play a vital role.
\end{abstract}

Keywords: competence, capability, framework, TEL, toolkit, education, well-being

Received on 14 January 2017, accepted on 06 June 2017, published on 20 June 2017

Copyright (C) 2017 Biggins et al., licensed to EAI. This is an open access article distributed under the terms of the Creative Commons Attribution licence (http://creativecommons.org/licenses/by/3.0/), which permits unlimited use, distribution and reproduction in any medium so long as the original work is properly cited.

doi: 10.4108/eai.20-6-2017.152742

\section{Introduction}

Despite the number of efforts in promoting and developing digital competence across varying social spheres such as education, health and policy, the study Measuring Digital Skills across the EU (2014) found that $47 \%$ of the EU population has insufficient digital skills, whilst $23 \%$ has none at all, as well as that $39 \%$ of the EU workforce has insufficient digital skills with $14 \%$ having no digital skills, and lastly $64 \%$ of disadvantaged people (aged 55-74, low educated, or unemployed) have an insufficient level of digital skills and $38 \%$ have no digital skills at all [1]. The study adds that information and communication skills are higher than content creation and problem-solving skills among the EU population. This represents a key challenge for institutions educating young adults. Although college and university students often seem technologically competent, they might have a narrow knowledge and set of skills connected to specific platforms (e.g. social networks) and technologies (e.g. mobile phones) [2a, b] , as well as a limited awareness of opportunities and issues these can potentially bring to their personal and professional lives [3].

It however is not digital competence or capability that is important in the context of higher education, but inclusive, effective, life-long learning. This should act as an enabler and encompass the learning of staff and students that it embodies. Education of all levels is preoccupied with complex literacy and the ability to navigate self-learning for continuous development [4]. Digital competence and capability therefore plays, or should play, an essential role in both enhancing immediate, and enabling life-long, learning. Recognising this, EU and distinct local organisations - such as Jisc in the UK - have developed and acknowledged a number of digital competence and literacies frameworks for the purpose of encouraging and underpinning various educational and other initiatives. This paper reviews the frameworks, positions

"Corresponding author: dbiggins@bournemouth.ac.uk 
them within the HE context and explores their practical implications through a single UK institution case study of a technology enhanced learning toolkit.

\section{EU-Commissioned Digital Competence Frameworks}

The European Parliament and the Council published recommendations on key competences for lifelong learning that included digital competence in 2006, whilst defining competence as 'a combination of knowledge, skills and attitudes' and clarifying that key competences are those 'which all individuals need for personal fulfilment and development, active citizenship, social inclusion and employment' [5]. This life-long learning reference framework approaches digital competence as a confident, informed, critical, reflective, responsible, ethical, and legal use of Information Society Technology (IST) - its tools and complex information - for personal, cultural, social, creative, innovative, and/or professional purposes.

The EU established here that digital competence penetrates all aspects of life at all stages, but there was no strategic framework in place until Europe 2020 and its Digital Agenda (2010) made of seven pillars with one being 'promoting digital literacy, skills and inclusion' [6]. The Digital Competence (DigComp) project was commissioned by the EU DG for Education and Culture in 2011, leading to the publishing of the first The European Digital Competence Framework for Citizens framework two years later [7]. The Tables 1 a 2 below summarise and compare the core areas of the digital competence frameworks from 2013 and 2016 developed and updated by the Joint Research Centre (JRC) of the European Commission.

\section{Table 1. Digital competence frameworks 1.0}

\section{DigComp 1.0 (2013)}

\begin{tabular}{l} 
1. Information \\
\hline Browsing, searching and filtering information \\
Evaluation information \\
Storing and retrieving information
\end{tabular}

\section{Communication}

Interacting through technologies

Sharing information and content

Engaging in online citizenship

Collaborating through digital channels

Netiquette

Managing digital identity

\section{Content creation}

Developing content

Integrating and re-elaborating
Copyrights and licences

Programming

4. Safety

Protecting devices

Protecting data

Protecting health

Protecting the environment

5. Problem solving

Solving technical problems

Identifying needs and technological responses

Innovating and creatively using technology

Identifying digital competence gaps

Table 2. Digital competence frameworks 2.0

\section{DigComp 2.0 (2016)}

\section{Information and data literacy}

Browsing, searching and filtering data, information and digital content

Evaluating data, information and digital content

Managing data, information and digital content

2. Communication and collaboration

Interacting through digital technologies

Sharing through digital technologies

Engaging in citizenship through digital technologies

Collaborating through digital technologies

Netiquette

Managing digital identity

3. Digital content creation

Developing digital content

Integrating and re-elaborating digital content

Copyright and licences

Programming

\section{Safety}

Protecting devices

Protecting personal data and privacy

Protecting health and well-being

Protecting the environment

5. Problem Solving

Solving technical problems

Identifying needs and technological responses

Creatively using digital technologies

Identifying digital competence gaps 
The proposed changes, firstly, put more emphasis on 'digital technologies' and 'digital content' whilst introducing 'data literacy' and 'collaboration', and secondly, clarify and extend the safety area. The stress on digital technologies replacing terms such as 'online', 'ICT', and 'channels' reflects the increasing accessibility and use of varied networked digital devices such as smartphones, smart TVs and wearables [8], as well as their dialogic relationship [9]. The inclusion of digital content alongside 'information' arguably acknowledges the diversity and complexity of evolving digital environments directly connected to technological innovations (e.g. virtual reality) and social circumstances (e.g. right to be forgotten), subsequently making the framework more sustainable. Expanding communication to collaboration is certainly another step forward, which not only reflects the already existing industry and social practices, but further encourages active citizenship and new forms of social and civic participation.

The wider availability of data in different formats together with the spreading concerns about personal data protection and overall privacy are reflected in the inclusion of data literacy as well as in the updated version of the safety area. The changes in 'safety' have brought into the updated framework more balance between individual and collective (social) safety and well-being. Here the need for awareness about distinct issues related to the use of digital technologies (ranging from physical and psychological risks, through social inclusion, to environmental impact) is clearly identified. Moreover, although the inclusion of (physical, social and mental) well-being might be underpinned mainly by the EU health agenda penetrating a number of frameworks developed under distinct strategies (e.g. EU Youth Strategy [10]), it returns digital competence to its more complex and varied role in one's life as initially recognised by The European Parliament and the Council in 2006.

Well-being has also been recently added to the six elements of digital capability [11] developed by Jisc (Joint Information Systems Committee), a UK-based non-profit organisation providing frameworks and resources for strategic development of digital literacies within the higher and further education sector. The following section will further discuss the digital capability framework and compare it with DigComp.

\section{Digital Capabilities Framework in the UK HE and FE}

Beetham and McGill led the Jisc's Digital Capabilities (here referred to as DigCap) frameworks project in 2015, within which they reviewed over sixty frameworks and relevant websites and publications, while at the same time interviewing dozens of experts based in HE and the relevant industry spheres. The research found that there was a high awareness of the original seven elements of digital literacy published by Jisc in 2009 (see Figure 1) [11], which allowed the research participants to provide informed insights and recommendations. They for example suggested that 'different areas visibly overlap' and thus 'described a 'venn diagram" or 'flower with overlapping petals' as more appropriate' than the tabular approach used by the previous framework [12]. On this ground, a new diagram visualising the updated framework has been developed (see Figure 2).

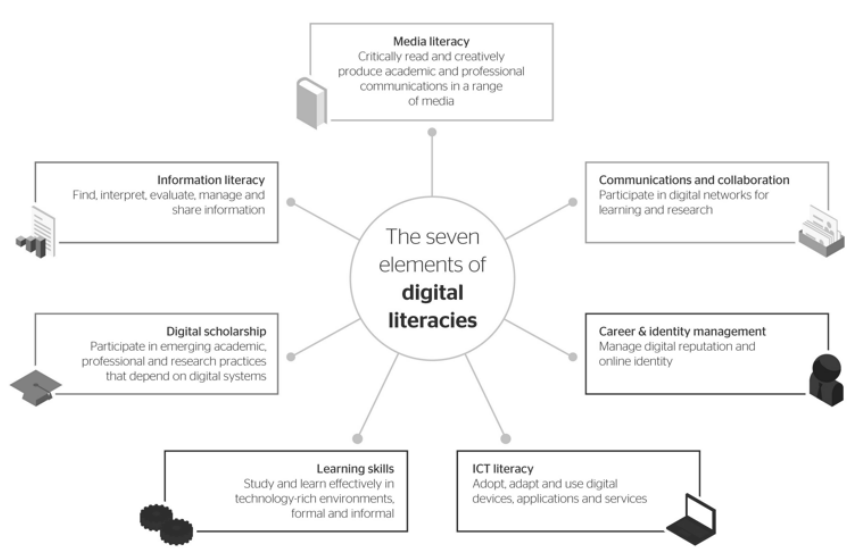

Figure 1 Seven capabilities of digital literacies introduced in 2009 [11]

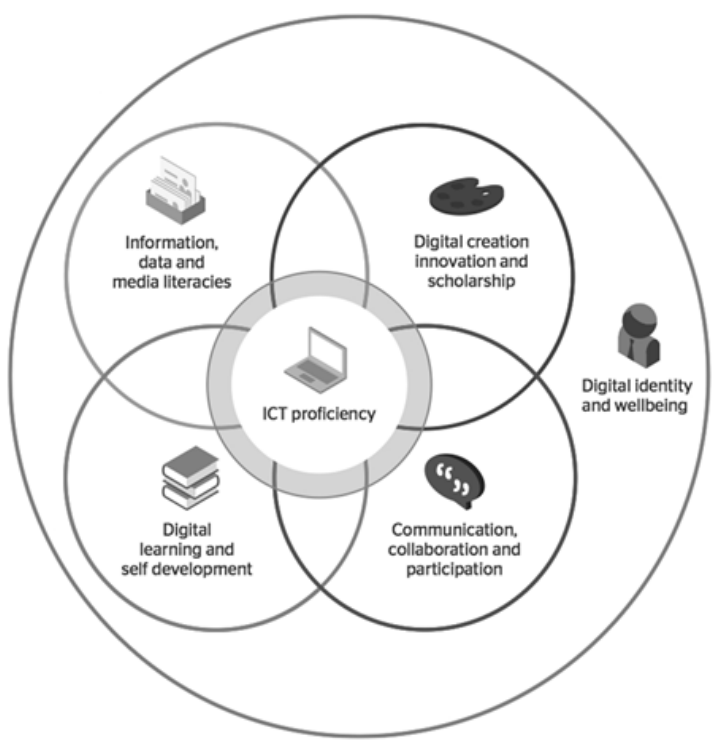

Figure 2 Digital capabilities framework and its six elements updated in 2015 [12]

When comparing the new DigCap framework with the previous seven elements of digital capabilities, the information and media literacies have been brought together and at the same time extended with data literacy. Jisc's DigCap and EU's DigComp frameworks therefore agree on the increased importance of 'data', which is also visible through the inclusion of 'data literacy' to DigComp. Whereas Jisc includes diverse literacies directly in the six core elements of DigCap, the EU instead links the DigComp's components to the UNESCO's media and information literacy (MIL) [13] and the Global Media and Information Literacy Assessment Framework [14] through tabular summaries included in the document's annexes.

DigCap 2009 and 2015 as well as DigComp 2013 and 2016 frameworks all stress the significance of digital 
creation, innovation, communication, collaboration, participation or engagement, and digital identity. In addition to these and, as mentioned earlier, the latest versions of the frameworks both added 'well-being'. DigCap justified this, on one hand, by the research finding that the expectations of staff to deliver 'digital practice' as a source of stress and concern among teachers (e.g. workload) and students (e.g. cyberbullying and time management, and on the other hand, by stating that ' $[\mathrm{e}]$ veryone can suffer if digital technologies are used without attention to human and environmental health, and without considering whether digital practices are fully inclusive and equitable' [15]. Whereas the first argument is grounded in Beetham and McGill's primary research, the second is fully consistent with the EU Digital Agenda's aim to build 'inclusive, equitable and sustainable European information society' [16] as well as with other EU frameworks (e.g. Education 2030: Incheon Declaration and Framework for Action towards inclusive and equitable quality education and lifelong learning for all [17]).

The difference in the frameworks' target audiences is visible in the DigCap's areas of scholarship, learning and development that belong among the key capabilities. It is understandable that DigCap for higher and further education can be more specific, whereas DigComp for all EU citizens must be more general. Despite that, learning and development is covered within DigComp's 'problem solving' area stressing the competence of identifying and evaluating needs and self-development opportunities that can be fulfilled through/with digital technologies. Furthermore, DigComp highlights the importance of understanding 'where one's own digital competence needs to be improved or updated', as well as to 'be able to support others with their digital competence development' [8]. One's own life-long learning as well as the support of others is therefore embodied in both frameworks despite their diverse contexts and target audiences.

The following section will use the case of Bournemouth University (BU) and its digital toolkit, which takes into account student and staff life-long learning, development and well-being, in order to discuss the practical implications of DigComp and DigCap.

\section{Technology Enhanced Learning and Self-Development: Case of BU's TEL Toolkit}

BU's digital toolkit, developed by the Centre for Excellence in Learning (CEL), will serve here as a case study that helps to illustrate abstract ideas through examples of real situations [18]. The case study approach is popular in educational research [19] as it allows a phenomenon such as digital competence and capability learning to be set within its context [20]; here being higher and further education in the UK and, by extension, the EU.

The mission of CEL is to make a significant contribution to the strategy of fusing education, professional practice and research by enhancing the student learning experience across the University, with one of the major themes being technology enhanced learning (TEL). This theme seeks to harness available technology to develop the competencies and confidence of staff and to engage and enthuse students in their learning and self-development activities. As Heppell (2016) argues, 'one significant impact of new technologies in education has been to give teachers and learners a voice through the many "bottom up" channels' [21]. Although TEL tools have been in use at BU for many years, their uncoordinated growth led to the situation where many, sometimes duplicate, tools were being used, the support was sporadic and information on the tools was spread across many university systems.

The TEL Toolkit was envisioned as a way of bringing together these disparate resources in one place so that staff, students, partner institutions and the wider academic community would know where to go for publicly accessible TEL information [22]. Support for and promotion of the Toolkit is provided by Learning Technologists and representatives from IT and Library, ensuring that the Toolkit is relevant and contemporary. Students interface with the Toolkit via the practice of lecturers and independently via exploration of the website, experiences that act to raise student expectations of the use of TEL.

An important aspect of the Toolkit is the six learning pedagogies it incorporates. The first four - blended learning, feedback and feedforward, flipped classroom, and assessment - are relevant to the EU's educational frameworks (e.g. European Framework for Digitally Competent Educational Organisations [23]) and Jisc's DigCap, whereas the remaining two - collaboration \& co-creation and engagement - are directly aligned with both DigCap and DigComp. For each area, there is an explanation of why the pedagogy is important to teaching and learning, how staff can use the approach and the TEL tools available to develop their practice.

The TEL Toolkit is supported by an online questionnaire based on the EU's DigComp and Jisc's DigCap models that enables staff to self-assess their confidence in using tools and their wider digital literacy awareness of the areas listed in Figures 1 and 2. The rationale for the questionnaire is twofold. The first is focused on teachers' well-being. By completing the questionnaire, staff gain a better understanding of their own digital skills and can identify areas for self-development through personalised support. This also enables them to access University workshops and training sessions, and this may reduce technology related stress. Secondly, CEL uses the information to make informed decisions about how and where to focus attention and invest resources to best support academic staff.

To date, almost $60 \%$ of academic staff have completed the questionnaire. The picture is constantly changing as more staff undertake the assessment and there is a general decline in confidence levels as academic staff who are more reluctant to engage in TEL are encouraged to participate in the assessment. Their generally lower levels of confidence are reducing the averages created by staff more engaged and confident with TEL who completed the questionnaire when it was first made available. Work continues to encourage the remaining $40 \%$ of staff to complete the questionnaire using a variety of techniques including raising awareness in meetings 
and via social media, creating a competitive environment between faculties and departments for completion rates and linking the assessment to events requiring completion prior to attendance. The fact that the questionnaire can be anonymous makes it impossible to discern who has or has not completed it and it is known that some people have completed it twice. As a voluntary activity, the various strategies deployed offer the best opportunity to gain a university-wide perspective but care is needed to guard against drawing conclusions and taking action on an incomplete dataset of responses.

From the analysis so far, it is clear that much more work is needed to support staff at BU. In the questionnaire, confidence is recorded on a scale: 1 = unaware; 2 = aware; 3 $=$ practiced $;=$ competent $5=$ proficient; $6=$ expert. Across all the tools in the Toolkit, the percentage confidence levels were: unaware $=32 \%$, aware $=27 \%$, practiced $=10 \%$, competent $=12 \%$, proficient $=12 \%$ and expert $=8 \%$. These findings reflect the fact that, because the TEL Toolkit was introduced in 2016, many staff are unaware of the tools available. This is to be expected and also demonstrates the fact that not every tool will be applicable to each teaching and learning environment. Staff report the highest levels of confidence (based on the most frequent responses) in aspects of the Virtual Learning Environment (VLE), Turnitin, using presentation equipment, Facebook, Skype and YouTube. Of the 33 tools in the list that can be used by teaching staff, 26 have a modal rating of aware or unaware. Included in this block are useful tools for lecture capture, audio recording presentations and reading lists.

When it came to wider digital skills, it is clear that staff have higher levels of confidence in general digital skills than exist for the TEL Toolkit. The modal answer was proficient. $81 \%$ of staff reported being enthusiastic about using technology and $51 \%$ said they were cautious about technology. However, most staff had also experienced a negative outcome from using technology and there was a significant but moderate correlation $(\mathrm{r}=0.328, \mathrm{p}<0.000)$ between those who experienced a negative outcome and those who are cautious about the use of technology. This demonstrates the importance of re-building confidence and well-being after a negative outcome while acknowledging that confidence, once diminished, takes time to rebuild.

In addition to the understanding being gained of staff's digital competency, the TEL Toolkit Working Group, which has responsibility for maintaining and developing the TEL Toolkit and processing the questionnaire responses, has been using response data to inform its actions. This has included the identification of previously unknown TEL champions within departments who are helping and supporting other staff as Vuorikari et al. [8] suggest, innovative tools that have subsequently been assessed and then added to the Toolkit for wider adoption and also concerns about the practical and pedagogic use of some tools for example in the area of peer and self-assessment. A further benefit of the questionnaire has been the identification of staff with similar interests who are being encouraged and supported to develop these interests into communities of practice and research opportunities. Examples include immersive and virtual reality and augmented reality with an emerging Community of Practice
(CoP) [24]. It is unlikely that these areas would have been uncovered so readily had there been no questionnaire.

The TEL questionnaire has also fed into the ongoing work around the investment in infrastructure. BU's IT services are refreshing all the AV equipment across the University, enhancing the affordances of an ambitious building programme, with a new student centre (2015), a new student learning building (2016), and three new building planned in the next three years. The start of 2017 sees the launch of our new VLE, Brightspace, from D2L. This decision marks a pivotal stage in a rigorous year-long procurement process. Competing suppliers were required to prove compliance in meeting over 200 functional/non-functional requirements, outline the service associated with BU's new platform, provide sandbox environments for staff and students to test, and to supply references from other Higher Education Institutions.

The forces of technology-capable and confident staff, heightened student expectations, and investment in infrastructure are driving TEL developments at BU and together these aim to enhance the student and staff development, well-being and continuous learning.

\section{Discussion and Conclusion}

Through comparing the original and updated versions of digital competence and digital capabilities frameworks, the paper discovered parallel changes in the fields of data privacy and data literacy as well as in the emphasis on well-being, life-long learning and self-development. Using BU's TEL Toolkit as a case study, the paper illustrated how technological tools and human learning, self-development and well-being must go hand in hand, rather than being seen as separate phenomena, when discussing and applying digital competence and capabilities frameworks in the context of higher and further education.

A welcomed and positive direction is the human-centred approach constructing 'human lives in terms of possibilities rather than deficits' [24] that penetrates both frameworks as well as a growing volume of recent research and practice in technology enhanced learning. If TEL is such a key area of learning and self-development, the HE and FE institutions should investigate whether it is feasible to make TEL compulsory so that TEL moves from an optional to a mandatory element of unit delivery. As the case study briefly highlighted, the ways in which TEL can rise in importance within an institution is through organisational leadership, a strategy that identifies the importance of TEL, support for staff and an embedding of the TEL philosophy in working practices such as objective setting and feedback gathering. Key to success however lays here in the human-centred approach prioritising staff and students' immediate and lifelong well-being rather than the mere use of digital tools.

The close relationship between digital capability /competence and well-being is possible to observe, for instance, in Alkire's [25] work that uses Sen's capability framework for the measurement of well-being. Alkire does not clearly define well-being, but the application of capability framework reveals his focus on 'psychological well-being' 
[26]. Components such as realisation of human potential and personal growth [27] relevant to self-development and lifelong learning reflect the broader themes introduced in this paper. It can be argued that, despite the Alkire focus on public policy, there potentially is a space for measuring the effectiveness of an institutional TEL toolkit in a similar way. In undertaking such an analysis, a new understanding of relationship between staff and students' digital capability/competence and potential stress 'tipping points' in the context of higher education could potentially be identified. Stress related to using (or not using) digital technologies, or 'digital stress', has been so far explored within well-being research in the work context [28] and home environment [29], whilst there is a gap of research on digital

\section{Acknowledgements.}

The authors would like to acknowledge Dr Riina Vuorikari from the Information Society Unit of the European Commission for her feedback on the drafts of this paper.

\section{References}

1. European Commission: Measuring Digital Skills across the EU: EU wide indicators of Digital Competence (2014)

2a. Evangelinos, G., and Holley, D., 2014(a). A Qualitative Exploration of the EU Digital Competence (DIGCOMP) Framework: A Case Study Within Healthcare Education. In: G. Vincenti, A. Bucciero and C. Vaz de Carvalho, eds., E-Learning, E-Education, and Online-Training (ELEOT) First International Conference, Lecture Notes of the Institute for Computer Sciences, Social Informatics and Telecommunications Engineering. Cham: Springer International Publishing, pp.85-92 (2014). doi: 10.1007/978-3-319-13293-8.

2b. Evangelinos, G., and Holley, D., 2015(b). A Qualitative Exploration of the DIGCOMP Digital Competence Framework: Attitudes of students, academics and administrative staff in the health faculty of a UK HEI. EAI Endorsed Transactions on e-Learning, 2(6), p.e1. doi: 10.4108/el.2.6.e1.

3. Láb, F., and Němcová-Tejkalová, A.: Journalist Education and Truth in the Digital Age: Why We Need Critical Digital Literacy. In Stocchetti, M., ed., Media and Education in the Digital Age: Concepts, Assessments, Subversions. Frankfut am Main: Peter Lang, pp. 105116. (2014)

4. Zezulkova, M.: Media learning in primary school classroom: Following teachers' beliefs and children's interests. In: Kotilainen, S., and Kupiainen, R., eds. Reflections on Media Education Futures, pp. 159-169 (2015)

5. The European Parliament and the Council of the European Union: Recommendation of the European Parliament and of the Council of 18 December 2006 on key competences for lifelong learning (2006)

6. European Commission: Digital Single Market Europe 2020 strategy https://ec.europa.eu/digital-singlemarket/en/europe-2020-strategy

7. European Commission: DIGCOMP: A Framework for Developing and Understanding Digital Competence in Europe (2013)

8. Vuorikari, R., Punie, Y., Carretero, S., and Van den Brande, L., 2016. DigComp 2.0: The Digital Competence stress in higher education [30]. As a research by Darabi et al. [31a,b] exploring well-being and stress among UK academics suggests, stress can also be motivational, leading to selfdevelopment and learning if coped with well, for example, with institutional support.

Therefore, the authors call for further significant research exploring TEL toolkit effectiveness, potentially in the context of HE staff and students' psychological well-being. Funding has been secured to further investigate the impact of TEL toolkits and the frameworks associated with these at higher education institutions in the UK and across the EU, led by BU and entitled 'An Ontology of digital toolkits' which will provide a framework for mapping to be shared across the sector.

Framework for Citizens. http://publications.jrc. ec.europa.eu/repository/bitstream/JRC101254/jrc101254 _digcomp $\% 202.0 \% 20$ the $\% 20$ digital $\% 20$ competence $\% 2$ 0framework\%20for\%20citizens.\%20update\%20phase \% 201.pdf

9. Woodfall, A., \& Zezulkova, M.: What 'children' experience and 'adults' may overlook: phenomenological approaches to media practice, education and research. Journal of Children \& Media; 10(1), pp. 98-106. (2016)

10. European Commission: Youth Strategy on Health and Wellbeing

http://ec.europa.eu/youth/policy/youth_strategy/health_ wellbeing en.htm

11. Jisc: Developing Digital Literacies (2009) https://www.jisc.ac.uk/full-guide/developing-digitalliteracies

12. Beetham, H.: Revisiting digital capability for 2015 . (2015)

http://digitalcapability.jiscinvolve.org/wp/2015/06/11/re visiting-digital-capability-for-2015/

13. UNESCO: Media and Information Literacy http://www.unesco.org/new/en/communication-andinformation/media-development/media-literacy/mil-ascomposite-concept/

14. UNESCO: Global Media and Information Literacy Assessment Framework http://unesdoc.unesco.org/images/0022/002246/224655e .pdf

15. Beetham, H., McGill, L., and Littlejohn, A.: Thriving in the 21st century: Learning Literacies for the Digital Age (LLiDA project) (2009)

16. Mansell, R.: Here comes the revolution - the European Digital Agenda. In Donders, K., Pauwels, C., and Loisen, J., eds. The Palgrave Handbook of European Media Policy. Basingstoke: Palgrave Macmillan, pp. 202-217 (2014)

17. European Commission: Education 2030: Incheon Declaration and Framework for Action towards inclusive and equitable quality education and lifelong learning for all (2015)

18. Jisc: Learning in a Digital Age Extending higher education opportunities for lifelong learning (2011)

19. Pepler, G., and Jeans, N.: Summary of Jisc Digital Student Skills Sector study: preliminary review of the Learner Focus Groups (2016)

20. Yin, R.K.: Case Study Research: Design and Methods. Thousands Oak: Sage. Quin (2009)

21. Heppell, S.: From Digital Literacy to Capability: Critical review (2016) 
22. Bournemouth University: The TEL Toolkit https://www1.bournemouth.ac.uk/about/centreexcellence-learning/tel-toolkit

23. Kampylis, P., Unie, Y.,m and Devine, J.: European Framework for Digitally Competent Educational Organisations.

http://publications.jrc.ec.europa.eu/repository/bitstream/J RC98209/jrc98209_r_digcomporg_final.pdf (2015)

24. Wenger, E.: Communities of practice: Learning, meaning, and identity. Cambridge: Cambridge University Press. (1998)

25. McDougall, J., Readman, M., and Wilkinson, P.: From Digital Literacy to Digital Capability http://www.cemp.ac.uk/downloads/From\%20Digital\%20 Literacy\%20to\%20Capability\%20-

\%20Project\%20Report.pdf

26. Alkier, S.: The Capability Approach and Well-Being Measurement for Public Policy (2015) http://www.ophi.org.uk/wpcontent/uploads/OPHIWP094.pdf

27. Ryff, C.D., and Keyes, C.L.M.: The structure of psychological well-being revisited. Journal of Personality and Social Psychology, 69, pp. 719-727, (1995)

28. Reinecke, L., and Oliver, M.B.: Media Use and WellBeing: Status Quo and Open Questions. In: Reinecke, L., and Oliver, M.B., eds. The Routledge Handbook of Media Use and Well-Being. Routledge: New York, pp. 3-13, (2017)

29. Sonnentag, S., and Pundt, A.: Media Use and Well-Being at the Work-Home Interface. In: Reinecke, L., and Oliver, M.B., eds. The Routledge Handbook of Media Use and Well-Being. Routledge: New York, pp. 3-13, (2017)

30. Hefner, D., and Vorderer, P.: Digital Stress: Permanent Connectedness and Multitasking. In: Reinecke, L., and Oliver, M.B., eds. The Routledge Handbook of Media Use and Well-Being. Routledge: New York, pp. 341-354, (2017)

31a. Darabi, M., Macaskill, A., and Reidy, L.: A qualitative study of UK academic role: positive features, negative aspects and associated stressors in a mainly teaching-focused university. Journal of Further and Higher Education, (2016) http://shura.shu.ac.uk/10284/

31b. Darabi, M., Macaskill, A., and Reidy, L.: Stress among UK academics: identifying who copes best? Journal of Further and Higher Education, (2016) http://shura.shu.ac.uk/10283/ 